\title{
MKWI 2016 in Ilmenau
}

Die Multikonferenz Wirtschaftsinformatik (MKWI) ist die größte deutschsprachige Konferenz auf dem Gebiet der Wirtschaftsinformatik. Seit mehr als einem Jahrzehnt treffen sich im zweijährigen Turnus Wissenschaftler, Praktiker und Studierende, die an aktuellen Entwicklungen von Informations- und Kommunikationstechnologien und ihren Anwendungen in einem ökonomischen Umfeld interessiert sind.

Im März 2016 findet die MKWI an der Technischen Universität Ilmenau statt, die in der Lehre und Forschung auf den Gebieten Technik, Wirtschaft und Medien auf eine über 100-jährige Tradition zurückblickt. Seit 1988 bildet die Universität sehr erfolgreich Wirtschaftsinformatikerinnen und Wirtschaftsinformatiker aus und gehört zu den Top-Wirtschaftsinformatik-Standorten in Deutschland.
Die Technische Universität lädt herzlich ein, um aktuelle und wichtige Themen und Herausforderungen der Wirtschaftsinformatik zu diskutieren. Der moderne Campus der TU Ilmenau bietet dafür mit seiner hervorragenden Infrastruktur einen idealen Austragungsort.

Weitere Informationen zur Teilnahme sowie das Konferenzprogramm finden Sie unter: www.mkwi2016.de

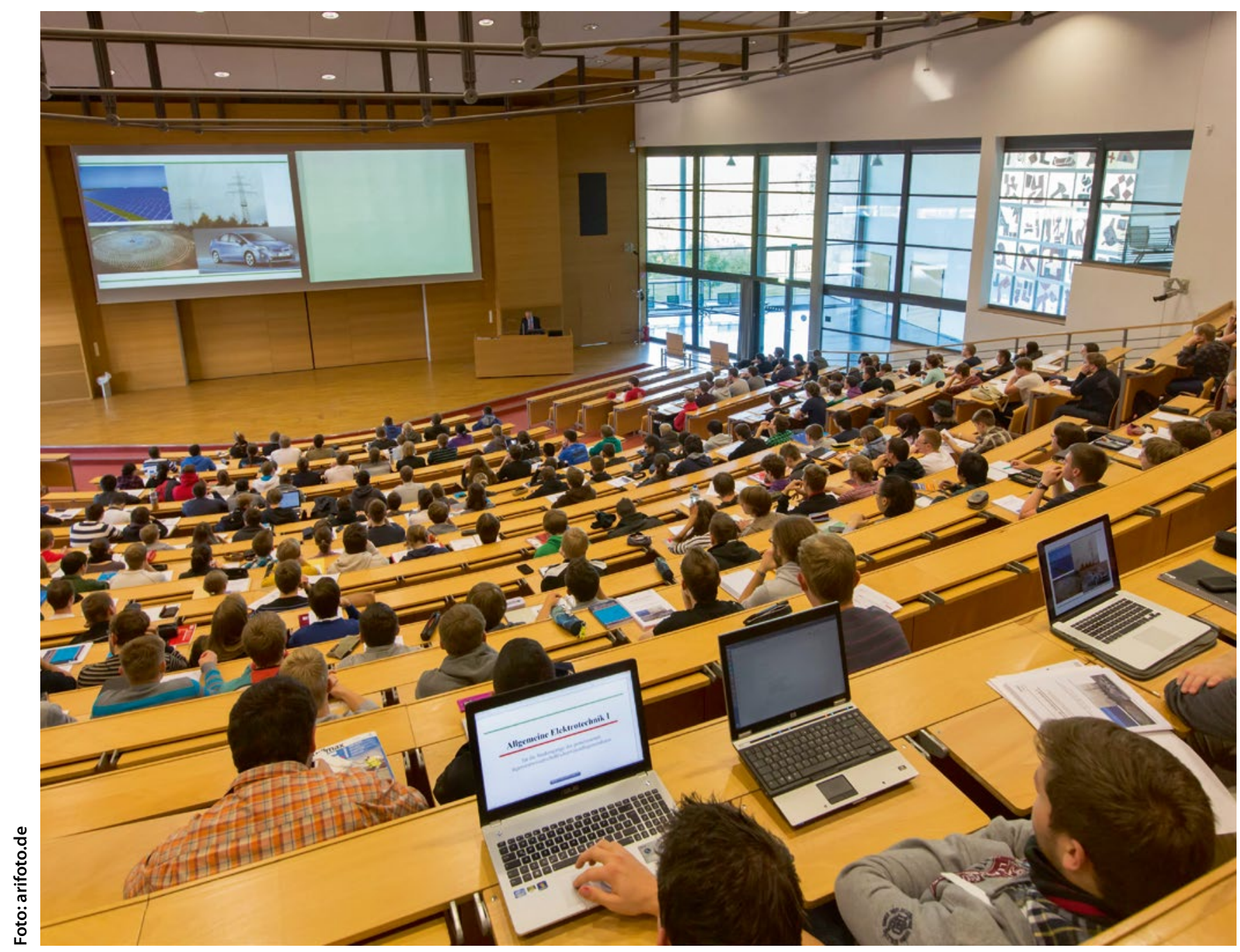

